\title{
Development of the Device with a High Positioning Accuracy Serving for Residual Stress Quantification using Optical Methods
}

\author{
Miroslav Pástor ${ }^{1, *}$, Peter Čarák ${ }^{1}$, Martin Hagara ${ }^{1}$ \\ Technical University of Košice, Faculty of Mechanical Engineering Letná 9, 04200 Košice, Slovakia
}

\begin{abstract}
The paper describes some procedures required for functional verification of a newly designed unique positioning device developed to quantify residual stresses by modern optical methods with a combination of the hole-drilling method based on ASTM-E 837-13a American standard. The high precision of milling a circular groove or a hole belongs to essential requirements for achieving relevant results in the quantification of residual stresses using semidestructive methods. At the beginning of the paper, the mechanical parts of the developed drilling device are briefly described. Subsequently, two analyses were realized and present in the paper. While the first one verifies the possibilities and accuracy of the cutter positioning in the vertical direction, the second one is focused on the investigation of the milled groove circularity. The results of both analyses are processed tabularly and prove the possibility to use the drilling device in residual stress analysis.
\end{abstract}

Keywords: experimental measurement, positioning accuracy, residual stress.

\section{Introduction}

As each manufacturing process leads to the occurring of residual stresses, they can be present almost in any structure and thus can be considered as one of the important factors of structural failure, especially in cases if the structure is exposed to variable operating loads or corrosive environment [1], [2], [3]. On the other hand, residual stresses can have also positive meaning, e.g. these produced by an operation known as shot peening, by which the occurring compressive stresses improve the mechanical properties of the material.

Taking into account that in real structures the residual stresses cannot be determined analytically, several experimental methods allowing their assessment were discovered. One of the most useful methods for determining residual stresses is a semidestructive hole-drilling method [4], [5]. As the residual stresses can be very dangerous when superposing with stresses from operational loading, it is necessary to asses them as accurate as possible. The inaccuracy of the measurement using the hole-drilling method has already been addressed, e.g. by Barsanti et. al [6] or Wang [7]. It has to be stated that the accuracy of the hole-drilling method is directly related to the proper positioning of the drilling tool to the centre of the special strain gage rosette. A study performed by Sandifer and Bowie [8] proves that the calculated uniaxial stress error does not exceed 3\% when the hole is not drilled more than $0.025 \mathrm{~mm}$ outside the rosette centre. To find the residual stresses distributed unevenly over the thickness of an analysed component, various correction coefficients have to be used [9], [10]. Mentioned parameters, required also for a case of eccentric drilling of the hole, are 
commonly determined using numerical modeling or experimental calibration.

Recently, a tendency to use the optical methods, especially Digital (Electronic) SpecklePattern Interferometry (DSPI, ESPI) or Digital Image Correlation (DIC) in combination with the holedrilling method can be observed [11], [12], [13]. Already at the turn of the 1960s and 1970s, the application of photoelasticity to determine stresses around drilled holes was described by Nisida [14] and Redner [15].

As the accuracy of the hole-drilling method depends mainly on selection of sensors and their installation, centring the tool and drilling the hole, instruments for measuring deformations, the following part of the paper will be focused on an experimental testing of a unique drilling device developed at the authors' department allowing assessment of the residual stresses using optical non-contact systems. The authors plan to test the proposed device for the determination of residual stresses in composites [16] or other modern materials used e.g. in the aviation industry [17].

\section{Testing of a developed unique drilling device}

The authors' workplace has concerned with several practice-oriented problems, by which the residual stresses have been determined using devices SINT MTS 3000 and RS 200 working on the hole-drilling method following ASTM E837-13a American standard [18], [19]. Besides, the author's workplace disposes of SINT MTS 3000 Ring-Core measuring system used mainly in laboratory conditions. In each of the mentioned methods, the residual stresses are assessed at the near surrounding of chosen location using special strain gage rosette. In comparison to the mentioned methodology, the optical methods provide a full-field analysis around a drilled hole or an annular groove [20], [21], [22]. On the other hand, the disadvantage can be seen in the fact that a high-precision positioning device is required for the experimental measurement of residual stresses to allow gradual drilling of the hole. For these reasons, the authors decided to design the unique device (Fig. 1) allowing quantification of residual stresses using optical methods by the procedure given in the standard ASTM E837-13a [23]. The device has been designed to allow drilling of a hole or an annular groove and to evaluate relaxed deformations in adjacent areas using PhotoStress ${ }^{\circledR}$ or Digital Image Correlation method.

Although the high precision of positioning is required mainly by the machining of components [24], it also belongs to the factors affecting the accuracy of the results obtained by the hole-drilling method. For positioning of the cutting tool, two ball screws $16 \times 5$ Rx3-4 with accuracy T5/0.023/300 mm were used. These screws rotate two servomotors of 8LVA23 type controlled by software. The feed parameter is 1 step $=1 / 1,000$ REV.

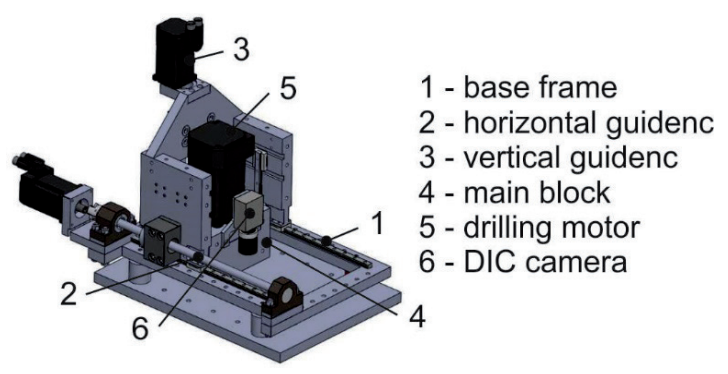

Figure 1: 3D model of the tested positioning device.

\subsection{Accuracy of the cutter positioning}

The experimental investigation was aimed to determine the accuracy of drilled annular grooves, taking into account the clearances of the drilling device mechanical parts, such as ball screws, bearing bodies, coupling and also own-weight of propelled parts, etc. For all the measurements, the specimen made from ENAW5083 material was used. The annular grooves were drilled using a milling cutter from the manufacturer of SINT MTS 3000 Ring-Core, which is based on the groove method. The outside diameter of the cutter is $18 \mathrm{~mm}$ and the inside diameter is $14 \mathrm{~mm}$.

The experimental measurement procedure included the drilling of the annular grooves with varying depth set in the control software of the drilling device. During milling, vertical displacement of the milling cutter was measured by a calibrated inductive displacement transducer HBM WA-50mm and a centesimal analogue dial indicator with $0.01 \mathrm{~mm}$ accuracy. The maximum deviation of the mentioned inductive displacement transducer measured between the start point and endpoint, indicated by the manufacturer is $\pm 0.2 \%$. The developed unique positioning device with applied measuring instruments is shown in Fig. 2. The drilling parameters set for each location can be found in Table 1. 


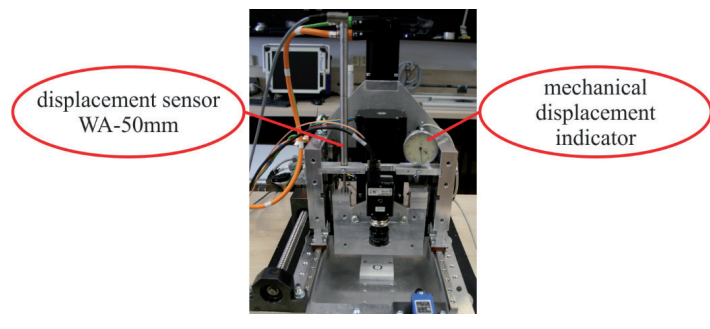

Figure 2: Measuring instruments applied to the positioning device.

Table 1: Parameters for the drilling of annular grooves.

\begin{tabular}{|l|l|l|l|l|l|l|}
\hline \multirow{2}{*}{} & \multicolumn{7}{|c|}{ Location } \\
\cline { 2 - 8 } & $I$ & $I I$ & $I I I$ & $I V$ & $V$ & $V I$ \\
\hline Total groove depth $(\mathrm{mm})$ & 0.2 & 0.5 & 1.0 & 1.0 & 1.0 & 1.0 \\
\hline Total number of divisions* & 40 & 100 & 200 & 200 & 200 & 200 \\
/ number of steps & $/ 20$ & $/ 25$ & $/ 50$ & $/ 50$ & $/ 50$ & $/ 50$ \\
\hline Step (mm) & 0.01 & 0.02 & 0.02 & 0.02 & 0.02 & 0.02 \\
\hline
\end{tabular}

*1000 divisions correspond to 1 revolution of the used ball screws, which causes 5 mm displacement

At the beginning of each measurement, the cutter was lowered freely to contact the surface of the specimen (Fig. 3). The output from the inductive displacement transducer was recorded by the strain gage amplifier Quantum. Before every measurement, both measuring instruments were balanced/set to zero (Fig. 4).

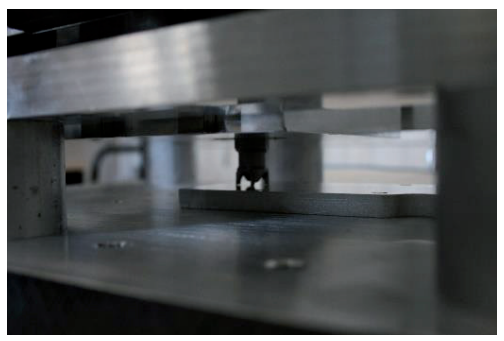

Figure 3: Starting position of the cutter.

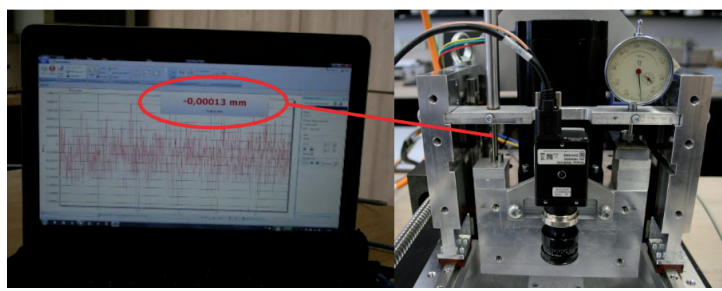

Figure 4: Balance of the measuring instruments.

After adjusting all the parameters, six grooves (Fig. 5) were milled to the desired depth (see Tab. 1).

The change of the vertical position of the cutter

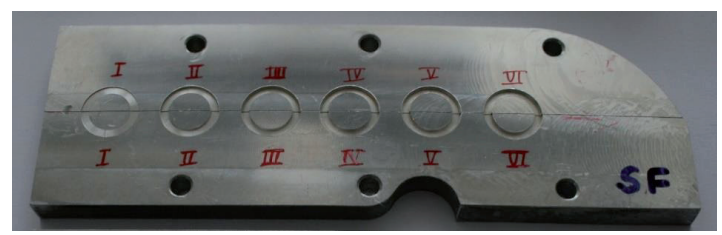

Figure 5: Analysed specimen with milled grooves.

in time was registered by Quantum during the entire measurement. Fig. 6 presents an example of time recording for vertical displacement of the milling cutter during milling. In area $\mathrm{A}$, the cutter displacement was set to $0.5 \mathrm{~mm}$ (100 divisions). As indicated in the graph (see Fig. 6), the value registered by the inductive displacement transducer was $0.4495 \mathrm{~mm}$. Such deviation was caused by the clearance of device mechanical parts. In zone B, the servomotor was actuated together with the milling cutter. After ca. 85 seconds (area C), the milling cutter was gradually lowered to contact the specimen surface. Lowering was performed in several steps. The contact occurred after 155 seconds. It was determined that the contact occurred after 0.425 mm (85 divisions) displacement and not after 0.5 mm (initial milling cutter stroke). The achieved position was taken as a reference one and the depth of the annular groove was measured here from. The groove depth was set to $1.0 \mathrm{~mm}$ corresponding to 200 divisions. The milling was performed gradually in 50 steps (area D). After ca. 985 seconds, the milling was completed and the position of milling cutter was set to starting one (area E).

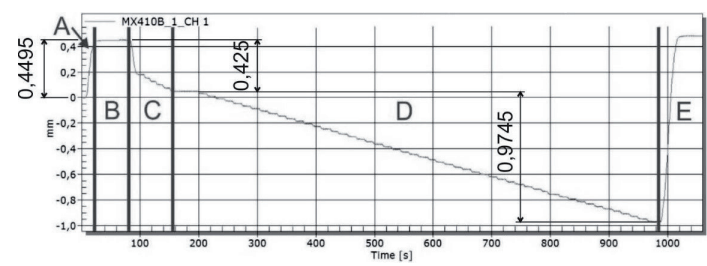

Figure 6: Recording the time of vertical offset during groove milling at location IV.

Table 2 shows the final depth values recorded by the inductive displacement transducer and the analogue dial indicator in every location. According to HBM assessment of calibration no. 171710317, the displacement deviation of HBM WA-50mm reaches $\pm 0.09 \%$. It has been noted that the values achieved by the analogue dial indicator (with displacement deviation $\pm 0.5 \%$ ) were recorded by the experimenters manually. 
Table 1: Mechanical properties of DC06 deep - drawing quality steel.

\begin{tabular}{|c|c|c|c|c|c|c|}
\hline & \multicolumn{6}{|c|}{ Location } \\
\hline & 1 & $\|$ & III & IV & V & $\mathrm{Vl}$ \\
\hline \multirow{3}{*}{$\begin{array}{l}\text { External diameter X } \\
(\mathrm{mm})\end{array}$} & 18.046 & 18.072 & 18.054 & 18.060 & 18.142 & 18.062 \\
\hline & 18.055 & 18.09 & 18.049 & 18.064 & 18.027 & 18.082 \\
\hline & 18.079 & 18.091 & 18.061 & 18.067 & 18.037 & 18.086 \\
\hline Mean value $(\mathrm{mm})$ & 18.060 & 18.084 & 18.055 & 18.064 & 18.069 & 18.077 \\
\hline \multirow{3}{*}{$\begin{array}{l}\text { External diameter } Y \\
(\mathrm{~mm})\end{array}$} & 18.006 & 18.055 & 18.054 & 18.066 & 18.055 & 18.08 \\
\hline & 18.016 & 18.071 & 18.053 & 18.073 & 18.072 & 18.018 \\
\hline & 18.005 & 18.093 & 18.067 & 18.016 & 18.082 & 18.04 \\
\hline Mean value (mm) & 18.009 & 18.073 & 18.058 & 18.052 & 18.070 & 18.046 \\
\hline \multirow{3}{*}{$\begin{array}{l}\text { Internal diameter X } \\
(\mathrm{mm})\end{array}$} & 13.215 & 13.188 & 13.195 & 13.167 & 13.226 & 13.173 \\
\hline & 13.217 & 13.183 & 13.199 & 13.183 & 13.217 & 13.166 \\
\hline & 13.207 & 13.183 & 13.197 & 13.19 & 13.193 & 13.171 \\
\hline Mean value $(\mathrm{mm})$ & 13.213 & 13.185 & 13.197 & 13.180 & 13.212 & 13.170 \\
\hline \multirow{3}{*}{$\begin{array}{l}\text { Internal diameter Y } \\
(\mathrm{mm})\end{array}$} & 13.199 & 13.186 & 13.178 & 13.195 & 13.169 & 13.045 \\
\hline & 13.190 & 13.176 & 13.18 & 13.184 & 13.180 & 13.028 \\
\hline & 13.174 & 13.174 & 13.178 & 13.190 & 13.188 & 13.037 \\
\hline Mean value (mm) & 13.188 & 13.179 & 13.179 & 13.190 & 13.179 & 13.037 \\
\hline
\end{tabular}

Table 2: Final depth values recorded by the inductive displacement transducer and the analogue dial indicator.

\begin{tabular}{|c|l|l|l|l|l|l|}
\hline \multirow{2}{*}{} & \multicolumn{7}{|c|}{ Location } \\
\cline { 2 - 7 } & $I$ & $I I$ & $I I I$ & $I V$ & $V$ & $V I$ \\
\hline $\begin{array}{c}\text { Set value } \\
(\mathrm{mm})\end{array}$ & 0.2 & 0.5 & 1.0 & 1.0 & 1.0 & 1.0 \\
\hline $\begin{array}{c}\text { WA-50mm-T } \\
(\mathrm{mm})\end{array}$ & 0.2114 & 0.5069 & 0.9862 & 0.9745 & 0.9651 & 0.9731 \\
\hline $\begin{array}{c}\text { Dial indicator } \\
(\mathrm{mm})\end{array}$ & 0.21 & 0.51 & 0.99 & 0.98 & 0.97 & 0.98 \\
\hline
\end{tabular}

Although the results do not correspond to the set groove depth, it can be stated that the values recorded by the inductive displacement transducer and the analogue dial indicator show a very good agreement in every single measurement. The absolute value of deviation can be corrected at the beginning of the measurement. As shown in Fig. 6, individual increments (steps) are the same and thus fulfil one of the conditions of quantifying residual stresses, namely to know the groove depth corresponding to released relative deformations on the surface of the component being analysed.

\subsection{Measurement of milled groove circularity}

The following testing was focused on the investigation, whether the circular annular groove is achieved by milling. The measurement consisted of a process to specify the position of four points located on the outside and inside diameters of the groove, turned by $90^{\circ}$ relative to each other (Fig. 7a), from which the diameter of the milled groove was determined in two mutually perpendicular directions.

Mitutoyo 176 electron microscope with 22.5x magnification was used for the measurement (see Fig. 7b). Three measurements were done for every examined diameter. The obtained values can be found in Table 3.

(a)

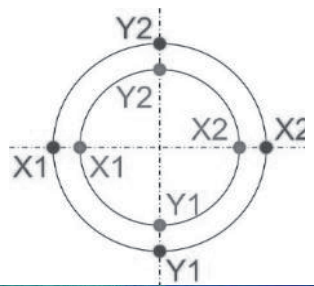

(b)

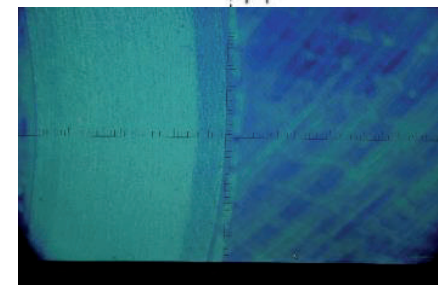

Figure 7: a) Position of measured points along the circumference of the annular groove, b) measurement of position X2 using Mitutoyo $176 \mathrm{~V}$. 
Data presented in Table 3 indicates that a groove has been formed with the outer diameter of ca. $18.059 \mathrm{~mm}$ and the inner diameter of ca. $13.176 \mathrm{~mm}$ (mean values fromall the measurements). Deviation of the groove internal diameter is caused by the shape of used cutting inserts because by milling there is a high probability that the material is pushed towards the centre of the groove. Taking into account that analysed distances directly on the specimen surface were measured under the microscope, they do not correspond to the internal diameter of the applied $14 \mathrm{~mm}$ miller. In spite of measured deviations, it can be stated that a circular annular groove has been formed at each location from I up to VI.

\section{Conclusions}

To determine residual stresses, the strain gage method belongs to one of the most used methods in technical practice, either for a through-hole method, a blind-hole method or a groove method. In any case, the ASTM E837-13a suggests the determination of residual stresses by the evaluation of released relative deformations as a function of the drilling depth of the drilled hole or groove. The advantage of today's modern measuring devices is that the set depth, as well as the number of drilling steps, is controlled by software. The disadvantage can be seen in the fact that on the real (analysed) object it is often impossible to determine the actual depth of the hole or the groove. It is not yet necessary to determine specific values of drilling increments.

The authors present in the paper that it is necessary to pay increased attention not only to preparation and execution of the experimental measurement and error analysis of measured data (statistical deviations) but also to observe manufacturer instructions - calibrate equipment, use appropriate cutting tools according to the type of material to be examined, etc. Achieved results support the fact that developed positioning device has the potential to quantify residual stresses not only by optical methods but after a slight structural modification (addition of positioning in the third axis) also for use by strain gage method. Fig. 8 illustrates the application of the proposed device within the determination of simulated uniaxial tensile stresses by the PhotoStress ${ }^{\circledR}$ method.

At present, there is a tendency to develop composite materials with improved mechanical properties while achieving a lower weight. Even in this field, there are possibilities to apply residual stress determination methods used so far, not only by the hole-drilling method but also by the nondestructive methods such as X-Ray method or others.

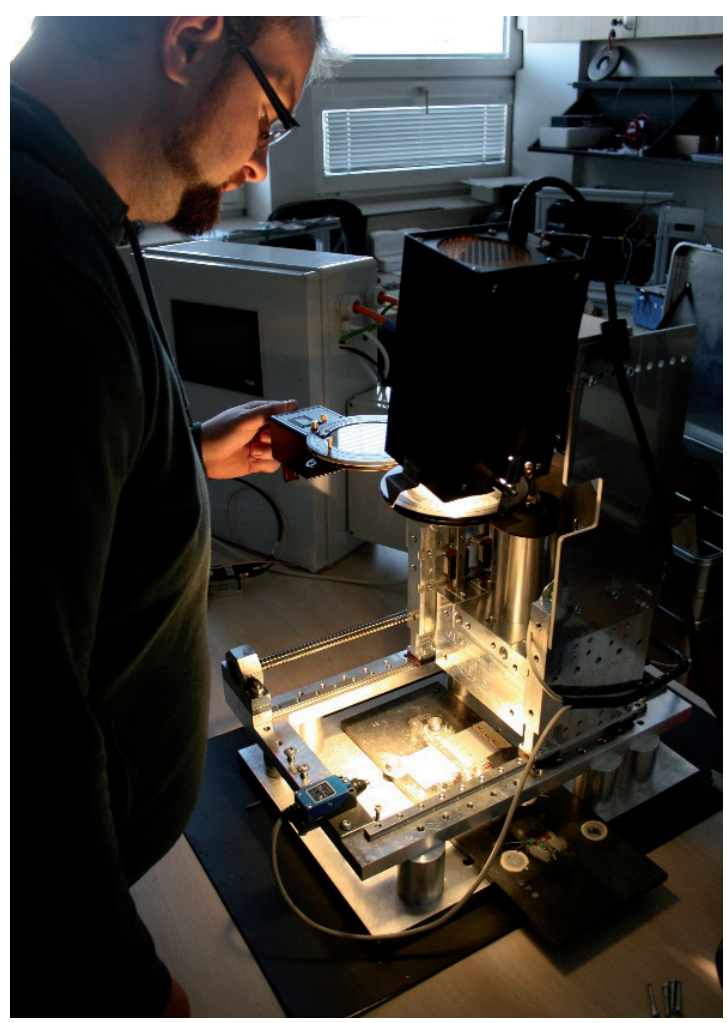

Figure 8: General view on the developed device with applied FLZ 2 based on PhotoStress ${ }^{\circledR}$ method.

\section{Acknowledgments}

This paper was supported by the project APVV 15-0435 and Operational Program Research and Innovation for the project: Module Research for Intelligent Robotic Systems, ITMS Code: 26220220141, co-funded by the European Regional Development Fund.

\section{References and Notes}

[1] Lothhammer, L. R., Viotti, M. R., Albertazzi, A., Jr., Veiga, C.L.N. Residual stress measurements in steel pipes using DSPI and the hole-drilling technique (2017), International Journal of Pressure Vessels and Piping, 152, pp. 46-55.

[2] Trebuňa, F., Šimčák, F., Bocko, J., Pástor, M. Analysis of causes of casting pedestal failures and the measures for increasing 
its residual lifetime (2013), Engineering Failure Analysis, 29, pp. 27-37.

[3] Wang, F. et al. Nondestructive evaluation of the residual stress via digital holographic photoelasticity (2018), Journal of Optics, 47 (4), pp. 547-552.

[4] Procter, E., Beaney, E. M. Recent Developments in Centrehole Technique for Residual-stress Measurement (1982), Experimental Techniques, 6, pp. 10-15.

[5] Rendler, N. J., Vignes, I. Hole-Drilling Strain Gage Method of Measuring Residual Stresses, Experimental Mechanics (1966), 6 (12), pp. 577-586.

[6] Barsanti, M., Beghini, M., Bertini, L., Monelli, B.D., Santus, C. First-order correction to counter the effect of eccentricity on the hole-drilling integral method with strain-gage rosettes (2016), Journal of Strain Analysis for Engineering Design, 51 (6), pp. 431-443.

[7] Wang, H.C.:The Alignment Error of the Hole-Drilling Method (1979), Experimental Mechanics 17, pp. 23-27.

[8] Sandifer, J. P., Bowie, G. E. Residual Stress by Blind Hole Method with Off-Center Hole (1978), Experimental Mechanics, 18 (5), pp. 173-179.

[9] Barsanti, M., Beghini, M., Santus, C., Benincasa, A., Bertelli, L. Integral method coefficients for the ring-core technique to evaluate non-uniform residual stresses (2018), Journal of Strain Analysis for Engineering Design, 53 (4), pp. 210-224.

[10] Menda, F., Šarga, P., Trebuňa, F. Estimation of residual stress field uniformity when using the Ring-Core method (2014), Residual stresses IX Book Series: Advanced Materials Research, 996, pp. 325-330.

[11] Pappalettere, C. A short survey on residual stress measurements by HDM and ESPI (2018) Conference Proceedings of the Society for Experimental Mechanics Series, 3, pp. 105-110.

[12] Ma, Y., Yao, X., Zhang, D. Axially symmetrical stresses measurement in the cylindrical tube using DIC with holedrilling (2015), Optics and Lasers in Engineering, 66, pp. 174-180.

[13] Schajer, G.S., Steinzig, M. Full-field calculation of holedrilling residual stresses from ESPI data (2005), Experimental Mechanics, 45 (6), pp. 526-532.

[14] Nisida, M. A Method for Measuring Stresses on Metal Surface with Photoelasticity (1965), Scientific Papers IPCR, 59 (2), pp. 69-77.

[15] Redner, S. Photoelastic Investigation of Stresses Relieved During Shallow Hole Drilling in Residual Stress Measuring Technology (1974), Proceedings of the International Conference on Methods of Experimental Mechanics, Prague, pp. 342-348.

[16] Valentini, E., Bertelli, L., Benincasa, A. Improvements in the hole-drilling test method for determining residual stresses in polymeric materials (2018), Materials Performance and Characterization, 7 (4), art. no. 123.

[17] Adamčík, F., Kabát, J., Schrötter, M., Jezný, M. Diagnostic of failures in aircraft airborne systems (2017), MOSATT 2017, TUKE, pp. 1-5.

[18] Šarga, P., Trebuňa, F., Šimčák, F., Bocko, J. Determination of the Possible Causes of Cracks in Pins of Quick Operating Valves in Hydroelectric Power Plant (2014), Residual stresses IX Book Series: Advanced Materials Research, 996, pp. 827832.

[19] Trebuňa, F., Šimčák, F., Bocko, J., Šarga, P., Trebuňa, P., Pástor, M., Mihok, J. Quantification of residual stresses in the weld by the hole-drilling method (2008), Metalurgija, 47 (2), pp. 133-137.

[20] Schajer, G.S., Winiarski, B., Withers, P.J. Hole-Drilling Residual Stress Measurement with Artifact Correction Using FullField DIC (2013), Journal of Experimental Mechanics, 53, pp. 255-265.

[21] Hagara, M., Trebuňa, F., Pástor, M., Huňady, R., Lengvarský, $P$. Analysis of the aspects of residual stresses quantification performed by 3D DIC combined with standardized holedrilling method (2019), Measurement: Journal of the International Measurement Confederation, 137, pp. 238256.

[22] Pástor, M., Frankovský, P., Hagara, M., Lengvarský, P. The use of optical methods in the analysis of the areas with stress concentration (2018), Strojnicky Casopis, 68 (2), pp. 61-76.

[23] ASTM E387-13a Standard test method for determining residual stresses by the hole-drilling strain-gage method, 2013. Annual Book of ASTM Standards American Society for Testing and Materials West Conshohocken.

[24] Palaščáková D., Demeč P. Working Precision of the Machining Centre (2018), Acta Mechanica Slovaca, 22 (2), pp. 54-59. 